\title{
Máscara e performance - literaturas lusófonas em diálogo: o desdobramento em heterônimos na lírica de Virgílio de Lemos, leitor de Fernando Pessoa
}

\author{
Mask and performance - lusophone literatures in dialogue: the unfolding into \\ heteronymous in the lyrics of Vírgilio de Lemos, reader of Fernando Pessoa
}

Universidade Federal de Viçosa, Viçosa, Minas Gerais, MG, Brasil.

\begin{abstract}
Resumo: este artigo apresenta uma análise do processo heteronímico na escrita do poeta Virgílio de Lemos. Discute-se, especificamente, a concepção poética dos três principais heterônimos virgilianos: Lee-Li Yang, Duarte Galvão e Bruno dos Reis. Virgílio de Lemos reitera, constantemente, ser profundo admirador e leitor atento da obra de Fernando Pessoa, atestando o diálogo intertextual com esse poeta português e com o jogo inovador proposto por ele no cenário das literaturas lusófonas no século XX. A metáfora da "máscara" está presente tanto no discurso de Virgílio de Lemos quanto no de Fernando Pessoa, portanto, pretende-se investigar como a dinâmica da encenação e da teatralização ocorre em alguns poemas desses escritores, importantes arautos das Literaturas de Língua Portuguesa. Palavras-chave: Virgílio de Lemos. Fernando Pessoa. Fingimento. Heteronímia. Máscara.

Abstract: this paper presents an analysis of the heteronimic process in the writing of the poet Virgilio de Lemos. The poetic conception of the three main virgilian heteronyms is discussed: Lee-Li Yang, Duarte Galvão and Bruno dos Reis. Virgilio de Lemos constantly reiterates that he is a profound admirer and attentive reader of the work of Fernando Pessoa, attesting to the intertextual dialogue with this Portuguese poet and to the innovative game proposed by him in the scenario of Lusophone literatures in the 2oth century. The metaphor of the "mascara" is present both in the discourse of Virgilio de Lemos and Fernando Pessoa, therefore, it is intended to investigate how the dynamics of staging and theatricality occurs in some poems of these writers, important heralds of Portuguese Language Literatures. Keywords: Virgilio de Lemos. Fernando Pessoa. Heteronimic. Mascara.
\end{abstract}

Para se refletir sobre a criação heteronímica em Virgílio de Lemos, é preciso considerar as peculiaridades da escrita imaginária de um autor que simula outras pesonalidades, cria indivíduos completos imaginados por ele, dando-lhes vidas próprias, profissões, características e estilos específicos que se revelam pela (na) escrita literária. A multiplicação em heterônimos reafirma a dissolução do sujeito em meio a outras vozes, instâncias discursivas; em artifício que, segundo Eneida Maria de Souza, “articula paradoxalmente o exilar-se e o habitar a linguagem pelo sujeito, ao se tornar tanto seu hóspede como seu anfitrião" (SOUZA, 2009, p. 411).
Discute-se, neste artigo, traços da concepção poética de Virgílio de Lemos \& heterónimos: Bruno Reis, Duarte Galvão e Lee-Li Yang - considerando os ciclos representativos da escrita desse autor moçambicano; especialmente, o que foi produzido entre 1944 e 1963, no período pré-independência de Moçambique. Virgílio de Lemos, leitor de Fernando Pessoa, propõe um jogo intertextual que reforça os trânsitos performáticos e os diálogos entre as literaturas lusófonas. Além desses três heterônimos, há outros, menos conhecidos, criados por Virgílio de Lemos quando ele residia na França: V. Klint (que escreveu poesia entre 1967 e 1973); V. Ernest (que 
redigiu um livro de análise política sobre a Guerra dos Sete Dias e a Palestina); e V. Altdorfer.

Rosicler Ferraz de Melo (2003), em texto intitulado O erotismo na poesia de Virgílio de Lemos (1944 a 1963): o eu que recorda, constata que, entre o ortônimo Virgílio de Lemos e seus heterônimos, há um elo: a atração pelo mar, pelo azul e pelas formas voluptuosas do corpo, que pode ser a representação do corpo feminino ou da terra. Há, também, a presença de mitos antigos, além de alusões a grandes nomes da Literatura de todos os tempos. A influência de autores clássicos e modernos, como Camões e Pessoa, faz-se sentir, mas, ao se lerem os versos do poeta moçambicano, a memória do já lido transmuda-se em sensação de novos movimentos, à semelhança da ondulação marítima.

Sobre o processo heteronímico do poeta moçambicano, Maria Nazareth Soares Fonseca, em Literaturas Africanas de Língua Portuguesa: percursos da memória e outros trânsitos (2008), afirma:

A produção dos vários heterônimos dá mostra da luta empenhada, via literatura, contra o "império da razão'; demonstra o esforço para acompanhar inovações trazidas pelas vanguardas europeias e pelo modernismo brasileiro e romper com os paradigmas coloniais. A leitura assídua da obra de Fernando Pessoa e o fato de também ter vivido, como o poeta português, em Durban, na África do Sul, dão o mote para que o poeta, por diversas razões, assuma várias feições e diferentes identidades, como tentativa de levar a extremo as propostas das vanguardas, sobretudo o surrealismo, e o seu desejo de opor-se aos padrões racionais vigentes no contexto moçambicano de sua época (FONSECA, 2008, p. 45).

Duarte Galvão, um apaixonado pela língua portuguesa e por Lourenço Marques, é o heterônimo mais engajado socialmente, além de ser o mais rebelde. É a face mais preocupada com as temáticas sociais, "com os preconceitos étnicos, com a miséria e com as injustiças" (FONSECA, 2008, p. 45). Duarte Galvão assinou os poemas do livro Poemas do tempo presente, interditado e apreendido pela Polícia Internacional de Defesa do Estado (PIDE), em 1960, sob a acusa- ção de ter insultado a bandeira nacional, órgão da soberania. $\mathrm{O}$ aspecto social, porém, não impede o desejo de expressão lírica dos sentimentos íntimos.

A sensualidade erótica, por sua vez, é uma característica da lírica de Lee-Li Yang, uma vez que, em seus poemas, o erotismo do corpo se transfigura em arma para a libertação feminina, desdobrando-se em expliração do ritmo e da visualidade. Curiosamente, os poemas de Lee-Li Yang foram dedicados ao seu amado, Duarte Galvão

Bruno dos Reis, por seu turno, escreveu poucos poemas e se manifestou, mais frequentemente, como cronista. Lemos justifica esse fato: "Vindo da poeticidade, é, entretanto, o heterónimo mais próximo de Ricardo Reis e também da crítica da história e da filosofia. Seus textos foram publicados, sobretudo, entre 1952 e 1953, no jornal Notícias da Tarde" (LEMOS, 1999, p. 147).

Foi o heterônimo Bruno dos Reis quem definiu: "a heteronímia é em si uma forma de vertigem" (REIS in LEMOS, 2009, p. 603). Essa percepção permitirá a discussão da heteronímia de Virgílio de Lemos e dos trânsitos desse poeta por sua constelação de vozes que reiteram sua errância e possibilitam a criação de um mundo poético rico em vozes e intertextualidades.

Os poemas de Lee-Li Yang, Duarte Galvão e Bruno dos Reis são, essencialmente, diferentes e concretizam propostas de criação poética que se distanciam da escrita ortônima de Virgílio de Lemos. Considera-se que, na criação virgiliana, a heteronímia se configura como um importante trânsito literário, na medida em que a performance do autor cria outras personalidades reais (embora sejam autores de papel), na tentativa de expressão de si próprio e de evocar a identidade fragmentada que se mostra em sua escrita que, por vezes, pode ser entendida como alusão à nação moçambicana.

Jean Baudrillard (1981), nas primeiras páginas do livro Simulacros e Simulação, apresenta uma fábula de Jorge Luís Borges como a mais bela alegoria da simulação. Nessa fábula, os cartógrafos do Império desenham um mapa de forma tão detalhada, que conseguem cobrir todo o território representado alegoria de como o duplo pode acabar se confundindo 
com o real. Baudrillard afirma: "Dissimular é fingir não ter o que se tem. Simular é fingir ter o que não se tem" (BAUDRILLARD, 1981, p. 9). A primeira ação remete à presença; a segunda, à ausência. Para esclarecer o segundo caso, o estudioso cita como exemplo alguém que simula ter uma doença, recolhe-se à cama e faz crer a todos que está mal. A simulação determina no sujeito algumas sugestões de sintomas; logo, para ele, "fingir ou dissimular deixam intacto o princípio da realidade: a diferença continua a ser clara, está apenas disfarçada; enquanto que a simulação põe em causa a diferença do verdadeiro e do falso, do real e do imaginário" (BAUDRILLARD, 1981, p. 10).

É necessário refletir sobre a questão: "O simulador está ou não doente se produz verdadeiros sintomas?" (BAUDRILLARD, 1981, p. 10). Nesse caso, o sujeito não pode ser tratado nem como doente nem como não doente. Fica o impasse para a Psicologia e para a Medicina: se qualquer sintoma pode ser simulado, então a doença também é simulável. Nesse contexto, surgem as doenças psicossomáticas e os sintomas passam do domínio do orgânico para o domínio do inconsciente. Supõe-se que esse sintoma (agora no domínio do inconsciente) é verdadeiro, mais verdadeiro que o outro. $O$ discurso de simulação não pode ser desmentido, porque também não é falso. O filósofo francês afirma: limítrofe é a distinção entre o verdadeiro e o falso, do sintoma produzido e do sintoma autêntico; "se ele imita tão bem um louco, é porque o é" (BAUDRILLARD, 1981, p. 11).

A representação parte do princípio de equivalência do signo e do real - mesmo que essa equivalência seja imaginária, é uma verdade primeira, um "axioma fundamental" (BAUDRILLARD, 1981, p. 11). Ao contrário da representação, a simulação parte da utopia, do fundamento da equivalência, relegando toda referência. Sobre esse aspecto, Jean Baudrillard conclui: "Enquanto a representação tenta absorver a simulação interpretando-a como falsa representação, a simulação envolve todo o próprio edifício da representação como simulacro" (BAUDRILLARD, 1981, p. 13).

Se um poeta ou romancista pode fingir (simular) uma vida inconsciente ou uma "vida interior" convin- cente para suas personagens, por que não pode criar também personas que produzem um trabalho criativo?

A obra de Virgílio de Lemos é, portanto, ainda mais transgressora dentro do panorama da literatura moçambicana. Demonstra estar em consonância com a moderna literatura ocidental, pautada pela disseminação do sujeito e pela alteridade. Lee-Li Yang, Duarte Galvão e Bruno dos Reis se apoderam das propriedades do gesto e da voz, encenando a essência do jogo do texto literário. A figuração intencional do poeta em múltiplos "eus" instaura um modo de ser que, como postula Souza, mostra "a sombra e o reflexo como imagens distorcidas do modelo, operação capaz de nomear tanto a literatura quanto a vida como domínios da representação e do artifício" (SOUZA, 2006, p. 102). Pode-se afirmar, então, que o exercício heteronímico reforça o pacto ficcional (a simulação), na medida em que "a vida do escritor se reverte necessariamente em grafia, e a biografia se traduz em literatura" (SOUZA, 2006, p. 102).

A criação heteronímica atribui radical modernidade à escrita desse poeta moçambicano, aproximando-a da escrita de grandes nomes, como Fernando Pessoa. Pode-se retomar, a propósito dela, o conceito de "fingimento", do poeta português, expresso no seu famoso poema "Autopsicografia": "o poeta é um fingidor, finge tão completamente, que chega a fingir que é dor, a dor que deveras sente" (PESSOA, 2002, p. 23).Esse recurso nos possibilita resgatar, também, emblemáticos versos do poema "Tabacaria", do heterônimo Álvaro de Campos, sobre o desdobramento e o descentramento do sujeito fabulador: "Que sei eu do que serei, eu que não sei o que sou? / Ser o que penso? Mas penso ser tanta coisa! E há tantos que pensam ser a mesma coisa que não pode haver tantos!" (CAMPOS, 2010, p. 397).

Eduardo Lourenço defende que "os heterônimos são a totalidade fragmentada e nenhuma exegese por mais hábil ou subtil a pode reconstruir a partir deles [...] É o mistério dessa ruptura que é necessário esclarecer e esclarecer concretamente" (LOURENÇO, 1974, p. 31). O poeta português fascina seus leitores por lhes apresentar uma obra multifacetada, e a sua heteronímia suscita a angústia do indivíduo moderno, 
fragmentado, ciente de que centramento e totalidade não passam de meras ilusões. As mais conhecidas personalidades poéticas criadas por Fernando Pessoa - Álvaro de Campos, Alberto Caeiro e Ricardo Reis - expressam as suas diferentes maneiras de estar no mundo por ideias, sentimentos e técnicas de composição poética. Cada um desses heterônimos têm identidade e características bem definidas: Álvaro de Campos é o poeta ligado ao futurismo, à modernidade e à velocidade de seu tempo; Alberto Caeiro busca retomar a essência e a simplicidade da natureza; e Ricardo Reis, por sua vez, utiliza-se dos recursos da linguagem e da sintaxe - transita do vocabulário erudito e arcaico às marcas da coloquialidade - além de fazer referências a deuses da mitologia grega.

Lélia Parreira Duarte [2010], ao destacar a presença da ironia na obra de Fernando Pessoa, acentua, nela, o processo de criação dos heterônimos: "Os heterônimos são máscaras, construções artificiais planejadas, que simulam soluções para a angústia da vida”. As máscaras citadas por essa pesquisadora retomam os conceitos de simulação e de fingimento, que pretendem "estabelecer comunicação e parecer resolver o problema da angústia e do medo da morte" (DUARTE, [2010]).

Fernando Pessoa escreve sobre a gênese de seus heterônimos e analisa o processo criativo dessas personalidades fictícias nos seguintes termos:

A origem mental dos meus heterônimos está na minha tendência orgânica e constante para a despersonalização e para a simulação. Estes fenômenos não se manifestam na minha vida prática, exterior, fazem explosão para dentro e vivo-os eu a sós comigo (PESSOA, 1992, p. 92).

Nota-se, nesse depoimento de Fernando Pessoa, que o "EU" íntegro do "Pessoa-criador" tem unidade pela pluralidade dos outros "eus". No poema "Primeiro Fausto", de Passagem das Horas, tem-se os seguintes versos: "Multipliquei-me, para me sentir, / Para me sentir, precisei sentir tudo, / Transbordei, não fiz senão extravasar-me, / Despi-me, entreguei-me / E há em cada canto da minha alma um altar a um deus diferente" (PESSOA, 1965, p. 345).
O poeta Virgílio de Lemos, em entrevista concedida a Carmen Lúcia Tindó Secco, publicada no livro Eroticus Moçambicanus (1999), explica as múltiplas identidades presentes em sua poesia e define o processo de produção de sua heteronímia, referindo-se a Sigmund Freud e a Fernando Pessoa, nestes termos:

No fundo, a heteronímia reflecte o que mais tarde Lacan designou como "descentramento do sujeito". Na errância, encontra-se a gênese da minha heteronímia, como dizia Bruno dos Reis, em 1952. Ou como Pessoa escreveu: 'na heteronímia reside a própria poesia'. De resto, a heteronímia é uma teia de fugas [...] Fugas, descentramentos, que se traduzem por multiplicações de personalidades e apetência de temas e formas, essência e subjectividade. Teia de fugas para escapar à censura e, mais que isso, ultrapassar o provincianismo colonial, abrindo Moçambique ao mundo, trazendo-lhe os ecos das vanguardas europeias, do Movimento PauBrasil, da Negritude, entre outras correntes surgidas nas primeiras décadas do século $\mathrm{XX}$ (LEMOS, 1999, p. 143).

No fragmento transcrito acima, o próprio poeta nos fala sobre o traço psicológico da criação dos seus heterônimos. Em suma, a heteronímia virgiliana consiste em uma genial construção de um universo literário plural. As "personas" por ele criadas encontram-se em desdobramento do seu "eu", reiterando o movimento de despersonalização. Por conseguinte, tanto na heteronímia pessoana quanto no processo criativo virgiliano, os "eus" gerados são dotados de gestos e discursos poéticos próprios, diferenciado-se da poesia ortônima de Fernando Pessoa e de Virgílio de Lemos. Esses dois poetas se mostram conscientes de que a simulação os conduz a um processo de despersonalização. A partir desse processo, o ser plural desdobra-se em heterônimos e acolhe outras vozes e gestos literários.

A influência da criação heteronímica de Fernando Pessoa na obra de Virgílio de Lemos é reiterada publicamente pelo escritor moçambicano em entrevistas e em poemas que celebram o poeta português. Virgílio de Lemos se declara leitor de Fernando 
Pessoa, tendo feito, inclusive, várias visitas a Durban, onde Pessoa viveu até os dezessete anos. Entre os poemas dedicados a ele, alguns trazem referências explícitas, como a "Ode a Fernando Pessoa", "Ode ao Portugal de Pessoa”, e "Ode a Camões e Fernando Pessoa”; há, também, referências indiretas, como "A tragédia da língua" - poema dedicado a Camões e Fernando Pessoa -, cujos versos enunciam "Sol, sendo luar, no desvelar reside / o segredo do criar, e na paleta / esquecida, vive ainda o morto, / duplo mergulho no texto e na deriva" (LEMOS, 1999, p. 68).

O primeiro texto citado, "Ode a Fernando Pessoa", Virgílio escreveu sentado na praia, diante da casa onde viveu o poeta português, em Durban, "olhando o mesmo mar que o poeta olhou aqui” (LEMOS, 2009, p. 451). Leiam-se, a propósito, os versos desse poema:

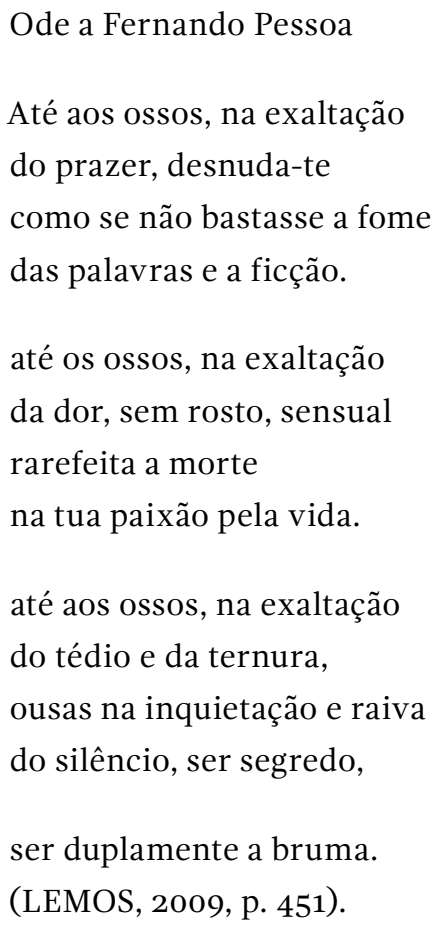

Em um dos fragmentos do poema "Haikus", assinado pelo heterônimo Bruno dos Reis, a alusão a Fernando Pessoa fica, também, implícita, mas pode ser constatada pela referência ao "guardador de rebanhos", livro-poema assinado por Alberto Caeiro (outro heterônimo de Fernando Pessoa). Vejamos:

O velho que encontro no caminho, guardador de [rebanhos
Me olha com espanto. E com espanto se deixa olhar!

Dentro da paisagem, eu - ou talvez o exótico? (REIS, 2005, p. 35)

Segundo Lemos, se há ou não semelhança entre a sua obra e a de Pessoa, caberá aos leitores e críticos literários descobrirem. Carmen Lúcia Tindó Secco considera que o processo heteronímico de Fernando Pessoa e de Virgílio de Lemos é bastante diverso, porque "Pessoa cria heterônimos bem diferentes entre si, cujos traços definidores não guardam identidade com sua biografia; já Virgílio projeta aspectos biográficos seus em um eu lírico estilhaçado em vários heterônimos" (SECCO, 2016, p. 185). Carmen Lúcia Tindó Secco prossegue a sua análise:

Há, na poesia de Virgílio de Lemos, um desejo de pluralidade, uma ansiedade constante, um esgarçamento interior também existentes na poética pessoana. Contudo, são bastante diferentes as inquietações e desassossegos vivenciados por Pessoa e Virgílio. Por exemplo, os poemas atormentados de Álvaro de Campos são perpassados por incomensurável angústia, imensa solidão, enquanto que os de Virgílio de Lemos e seus heterônimos são atravessados por forte erotismo e por um "insólito espanto" diante da existência (SECCO, 2016, p. 185).

Em consonância com o pensamento de Secco, Lélia Parreira Duarte reitera que o poeta português "apresenta múltiplas soluções heteronímicas para a angústia do homem que sabe não ter realmente um centro, uma "verdade", mostrando que essas soluções são máscaras, fingimentos [...]” (DUARTE, [2010]).

O empreendimento da modernidade heteronímica de Fernando Pessoa é retomado por Virgílio de Lemos no campo da representação e do fingimento. Não há dúvidas de que existe uma influência direta, já atestada, conforme assinalado anteriormente. Não obstante, é imperativo salientar algumas importantes diferenças: na heteronímia do poeta moçambicano, vê-se a encenação de um tempo e espaço bem definidos - "Dentro da paisagem, eu - ou talvez o exótico?" -; a sensualidade e o erotismo permitem 
uma outra leitura da realidade; o trânsito pelas ilhas moçambicanas e a reinvenção do Oceano Índico são algumas das características que conferem aos heterônimos virgilianos a originalidade aqui defendida.

Cumpre destacar, ainda, que, no fazer poético de Virgílio de Lemos, o que se vê é uma acepção radical do grau de fingimento literário. Lee-Li Yang, Duarte Galvão e Bruno dos Reis são diferentes máscaras poéticas forjadas por Lemos e, com apoio em Lélia Parreira Duarte, pode-se afirmar que se constituem como "máscaras que camuflam o mesmo vazio, o mesmo ser assujeitado às leis físicas e culturais, sendo essa poesia uma solução fingida e artificial” (DUARTE, [2010]).

A própria criação dos heterônimos é, fundamentalmente, um jogo palimpséstico, que pode ser explicado pela metáfora dos labirintos. Os heterônimos virgilianos não correspondem apenas a uma "persona" criada pelo escritor, mas a uma determinada posição artística e ideológica, que se reflete diretamente no modo da escrita. O fingimento está no cerne da criação poética, confirmando que os heterônimos revelam uma tendência constante à despersonalização e à simulação.

Para Bruno dos Reis, Duarte Galvão escreveu seu poema "Heterónimo", cuja interpretação é um grande desafio para os leitores. O "jogo do texto" - nos parâmetros propostos por Iser - está, aqui, encenado; evidenciando, sobremaneira, a singularidade poética de Virgílio de Lemos. Considera-se a proposta de Iser: "Assim o texto é composto por um mundo que ainda há de ser identificado e que é esboçado de modo a incitar o leitor a imaginá-lo e, por fim, interpretá-lo" (ISER, 2002, p. 107). No “jogo textual” proposto por Virgílio de Lemos, os heterônimos dialogam entre si, escrevem e trocam cartas uns com os outros, respondem cartas... Mas como entender o fato de um heterônimo sugerir a "morte" do outro? O poema "Heterónimo" suscita, nos leitores de Virgílio de Lemos, a consciência de participarem do jogo lúdico da linguagem.

É Duarte Galvão quem assume a enunciação do poema "Heterónimo" e, reflexivamente, declara: "Rasguei a máscara de Bruno dos Reis". Reafirmando o processo de interlocução, tem-se um "eu" que enuncia para um "tu”, característica comum na lírica virgiliana, que pode ser observada pela apreciação atenta de sua obra. No poema "Heterónimo", entretanto, as marcas do discurso sugerem, em alguns momentos, que "eu" e "tu" se confundem. Desde o título, é curiosa a opção pelo singular, "heterônimo" e não "heterônimos", uma vez que se trata de um diálogo entre duas "personas" virgilianas. Vejamos:

\section{Heterónimo}

Nesta tragédia de existir
Vou-me conhecendo a cada passo.
Rasguei a máscara de Bruno dos Reis
E chorei lágrimas de cansaço
De ter sido incoerente com o que sou;

Nota-se, no fragmento destacado, a busca pela identidade (de si e do outro?).

Rasguei mesmo todos os poemas liberais Que o Bruno dos Reis me ditou;

E hoje que é sexta-feira maior E fez anos que Cristo morreu Acentuou-se em mim a razão interior Que me fazia ateu; [...]

Reafirmando o fingimento poético e o jogo do texto, o eu lírico sugere que os seus próprios poemas foram ditados por Bruno dos Reis; entretanto, a melancolia o afasta de todas as crenças. A lucidez, advinda da melancolia, o faz reconhecer o "absurdo dos laços e dos seres" (KRISTEVA, 1987, p. 12) "acentuou-se em mim a razão interior":

Fiz logo exame de consciência E obriguei-me à penitência De me tornar Eu mesmo; Não importa o abismo que nasceu Entre mim, Bruno e o mundo; Importa, sim, haver uma razão Que torna o abismo profundo. Mas que parto infeliz? Que sensação De ferros penetrando em mim... Sinto-me perdiz feita presa Após a ressurreição.

Tornei-me finalmente Eu mesmo! 
Porém, que atroz confusão:

Vivendo comigo a esmo

Uma esmagadora certeza

Grita-me: Bruno dos Reis, tu mesmo!

Eu mesmo, irremediavelmente, Bruno!

(GALVÃO in LEMOS, 2010, p. 273).

Esse poema, assinado por Duarte Galvão, encena a complexidade da heteronímia de Virgílio de Lemos, que promove a teatralização da escrita literária. A sua dramatização é tão radical que seus "avatares" literários se encontram como fantasmas e parceiros da escrita desse "eu", que é múltiplo. Tem-se uma aventura existencial e ontológica: "Bruno dos Reis, tu mesmo! / Eu mesmo, irremediavelmente, Bruno!"; o jogo do texto traz a simulação de múltiplos sentidos dados ao "eu" que enuncia (Duarte Galvão, Bruno dos Reis ou o ortônimo Virgílio de Lemos?), além da própria simulação de sentidos evidente no título do poema: "Heterônimo". A heteronímia em Virgílio de Lemos pode ser caracterizada conforme afirma Lélia Parreira Duarte, em estudo sobre a obra de Fernando Pessoa: "Essa valorização da máscara, essa confissão de fingimento, essa consideração de que a normalidade está no uso da máscara fazem-nos suspeitar de que também os heterônimos seriam máscaras, mais do que soluções" (DUARTE, [2010]). A solução proposta por Duarte Galvão, "retirar a máscara de Bruno dos Reis", evidencia a consciência de uma época em que a tônica são o fingimento e a representação.

A máscara é a metáfora da performance e da possibilidade de "outrar-se" - ou seja: de tomar posse da personagem para nela atuar -, o que remete a tempos imemoriais. No teatro grego, por exemplo, as máscaras estabelecem relações com ritos primitivos, tornando-se objetos sagrados. É por intermédio delas que ressoa a voz do ator, o poder do verbo e da ação. Segundo Elizabeth Lopes, “despojado das suas feições mais expressivas, de seu potencial de comunicação: rosto e voz - o corpo do ator vai descobrindo recursos de expressão nunca experimentados, tornando-se aos poucos um rosto visto em close" (LOPES, 2010, p. 32). As máscaras do teatro grego também serviam para prender a atenção dos expectadores, expressando a essência do drama, perpetuando o clima mítico da tragédia e o grotesco da comédia. No decorrer do espetáculo, os atores trocavam de máscaras diversas vezes, porque cada uma representava determinada emoção ou estado da personagem. Em suma, a máscara teatral viva em cena é, em si, a própria essência do teatro. Ela é um arquétipo que leva o ator à representação e se fundamenta na despersonalização de quem a incorpora para simbolizar a pluralidade do ser humano, que pode assumir várias identidades. Como em um grande espetáculo teatral, o desdobramento de personalidades é uma característica inerente ao homem, que assume várias "personas" em sua vida cotidiana, desempenhando vários papeis no "palco do mundo".

Um poema de Álvaro de Campos, transcrito a seguir, também remete à metáfora da "máscara", do despir-se da máscara ficcional. Vejamos:

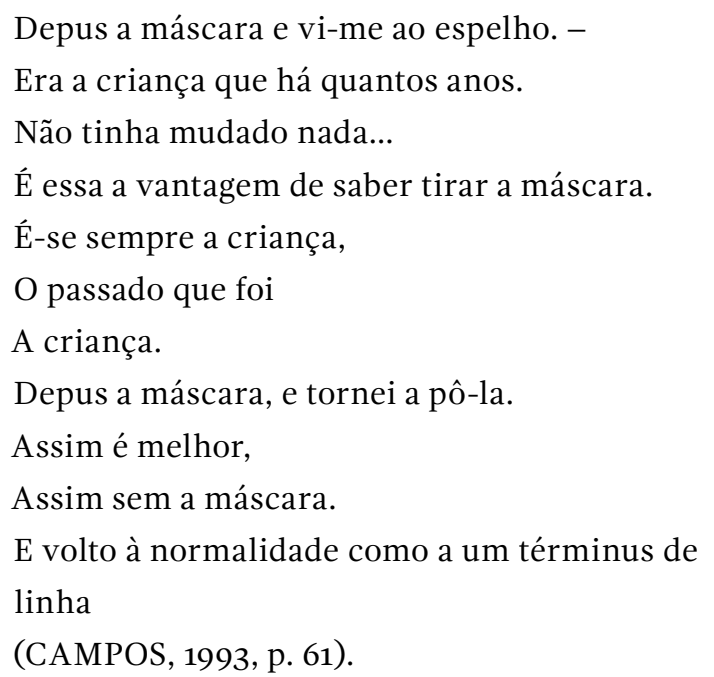

Nesses versos e em outros do já citado poema “Tabacaria” (CAMPOS, 2010, p. 397), faz-se referência à mesma metáfora: "Quando quis tirar a máscara, / Estava pegada à cara". Nos dois exemplos citados, ambos do heterônimo pessoano Álvaro de Campos, vê-se a analogia à teatralização que Virgílio de Lemos explicita em seu poema "Heterônimo". Os versos "Depus a máscara, e tornei a pô-la", "Quando quis tirar a máscara / Estava pegada à cara" e "Rasguei a máscara de Bruno dos Reis" reiteram o movimento de personalização e despersonalização no que tange à questão heteronímica. No primeiro caso, a máscara 
é retirada para retomar a infância; no segundo, não é possível despir-se das máscaras do fingimento. Nesse poema virgiliano, o heterônimo Duarte Galvão responsabiliza-se por retirar a máscara de Bruno dos Reis. O movimento de depor e repor as máscaras resgata movimentos teatrais, performativos e figurativos dos palcos, o que torna excepcional a obra de Virgílio de Lemos.

Analisando-se as várias vozes presentes no poema "Heterônimo" e na lírica virgiliana, constata-se que o jogo heteronímico está na estrutura da poesia de Virgílio de Lemos e que o desdobramento heteronímico marca um traço da personalidade desse poeta moçambicano. Como ele mesmo afirma em entrevista mencionada neste artigo, o fenômeno do desdobramento em outras "personas" pode ser explicado pela teoria lacaniana sobre o "descentramento do sujeito". A multiplicação das personalidades, a criação de autores de papel, são a essência da subjetividade de um poeta em trânsito pelos recursos estéticos, pelos espaços e temas que ecoam em suas letras.

Considerando-se todos os aspectos já discutidos, não há dúvidas do quanto o poeta Virgílio de Lemos foi vanguardista no contexto da poesia moçambicana. Abrir as letras moçambicanas a outras vozes, a outras influências era o desejo constantemente reiterado pelo escritor.

\section{Referências}

BAUDRILLARD, Jean. Simulacros e simulação. Tradução de Maria João da Costa Pereira. Lisboa: Relógio D’Água, 1981. (Coleção Antropos).

BENVEniste, Émile. Problemas de linguística geral I. Tradução de Maria da Glória Novak e Maria Luisa Neri. 5. ed. Campinas: Pontes Editores, 2005.

DUARTE, Lélia Parreira. Heteronímia e ironia em Fernando Pessoa. [S. l.: s. n., 2010]. Disponível em: http://www.leliaparreira.com.br/images/ensaios/heteronimia.pdf. Acesso em: 10 nov. 2017.

FONSECA, Maria Nazareth Soares; MOREIRA, Terezinha Taborda. Panorama das literaturas africanas de língua portuguesa. Cadernos CESPUC de Pesquisa, Belo Horizonte, n. 16, p. 13-69, 2007.

ISER, Wolfgang. A literatura e o leitor: textos de estética da recepção. In: LIMA, Luiz Costa (Org.). A literatura e o leitor: textos de estética da recepção. Tradução de Luiz Costa
Lima. 2. ed. rev. e ampl. São Paulo: Paz e Terra, 2002. p. 9-36. https://doi.org/10.11606/issn.2316-9141.v0i125-126p191-192

KRISTEVA, Júlia. Sol negro: depressão e melancolia. Tradução de Carlota Gomes. Rio de Janeiro: Rocco, 1987.

LEMOS, Virgílio de. Eroticus moçambicanus: breve antologia da poesia escrita em Moçambique (1944/1963). Rio de Janeiro: Nova Fronteira, 1999.

LEMOS, Virgílio de. Jogos de prazer. Lisboa: Imprensa Nacional, 2009.

LOPES, Elizabeth. A magia das máscaras: ator e seu duplo. In: BELTRAME, Valmor Níni; ANDRADE, Milton de (org.). Teatro de máscaras. Florianópolis: UDESC, 2010.

LOURENÇO, Eduardo. Pessoa revisitado: leitura estruturante de um drama em gente. Porto: Editorial Inova, 1974. https:// doi.org/10.11606/issn.2594-5963.lilit.1974.115786

MELO, Rosicler Ferraz de. O erotismo na poesia de Virgílio de Lemos (1944-1963): o eu que recorda. 2003. Dissertação (Mestrado em Literatura Portuguesa) - Faculdade de Letras, Universidade Federal do Rio de Janeiro, Rio de Janeiro, 2003 https://doi.org/10.21011/apn.2016.0602

PERRONE-MOISÉS, Leyla. A poética do ensaio. Revista Brasileira: Academia Brasileira de Letras, v. 2, n. 74, p. 9-14, 2013. Disponível em: https://livrozilla.com/doc/6022.35/ entrevista---machado-de-assis. Acesso em: 01 mar. 2018.

PESSOA, Fernando. Primeiro Fausto: passagem das horas. In: PESSOA, Fernando. Obra poética. Rio de Janeiro: Companhia Aguilar, 1965.

SECCO, Carmen Lúcia Tindó. Virgílio de Lemos e a linhagem pessoana de múltiplos eus. In: SANTOS, Gilda; OLIVEIRA, Paulo Motta. Genuína fazendeira: os frutíferos 100 anos de Cleonice Berardinelli. Rio de Janeiro: Bazar do Tempo, 2016 p. $185-198$.

Recebido em: 2/5/2019.

Aprovado em: 12/9/2019.

\section{\#34064}

SEÇÃO: ENSAIOS

\section{Luciana Brandão Leal}

Universidade Federal de Viçosa (UFV), Viçosa, Minas Gerais (MG), Brasil

Orcid: https://orcid.org/0000-0003-1534-9726

E-mail: luciana_brandao@hotmail.com

Endereço de correspondência: Rua Frei Junipero, 12. Bairro São Francisco. Pará de Minas (MG). CEP: 35661-165 